\title{
On the performance of birch tar made with different techniques
}

\author{
Patrick Schmidt ${ }^{1} 2^{*}$, Matthias A. Blessing ${ }^{1} \mathbb{C}$, Tabea J. Koch ${ }^{1} \mathbb{D}$ and Klaus G. Nickel ${ }^{2}$
}

\begin{abstract}
Birch tar is one of the oldest adhesives known in human history. Its production has been discussed in the framework of early complex behaviours and sophisticated cognitive capacities. The precise production method used in the Palaeolithic remains unknown today. Arguments for or against specific production pathways have been based on efficiency or process complexity. No studies have addressed the question whether birch tar made with different techniques is more or less performant in terms of its properties. We therefore investigate the adhesive performance of birch tar made with three distinct methods: the open-air condensation method and two variations of underground structures that approximate the double-pot method in aceramic conditions. We use lap-shear testing, a standard mechanical test used for testing the strength of industrial adhesives. Tar made in $1 \mathrm{~h}$ with the condensation method has a shear strength similar to, although slightly higher than, tar made underground if the underground process lasts for $20 \mathrm{~h}$. However, tars from shorter underground procedures ( $5 \mathrm{~h}$ ) are significantly less strong (by a factor of about 3). These findings have important implications for our understanding of the relationship between the investment required for Palaeolithic birch tar production and the benefits that birch tar represented for early technology. In this regard, the simple and low-investment open-air condensation method provides the best ratio.
\end{abstract}

Keywords: Early engineering techniques, Shear strength, Neanderthal modernity, Early pyrotechnology, Adhesives

\section{Introduction}

Birch tar is the oldest known adhesive dating back to the European Middle Palaeolithic. There are five pieces of birch tar known from the Palaeolithic record, all attributed to Neanderthals. The oldest two pieces were found in Campitello (Italy) and indirectly dated to $\sim 200 \mathrm{ka}[1]$. Two pieces were found at Königsaue (Germany) and estimated to between 40 and $80 \mathrm{ka}$ [2, 3]. The most recently found birch tar artefact comes from Zandmotor (The Netherlands) and is $\sim 50 \mathrm{ka}$ old [4]. At Inden-Altdorf (Germany), there are other artefacts with residues that were claimed to be birch tar [5] but detailed identification with Gas-Chromatography has yet to be undertaken. One of the questions surrounding these Palaeolithic birch

\footnotetext{
*Correspondence: patrick.schmidt@uni-tuebingen.de

${ }^{1}$ Department of Early Prehistory and Quaternary Ecology, Eberhard Karls University of Tübingen, Tübingen, Germany

Full list of author information is available at the end of the article
}

tar remains is how they were made in aceramic conditions. This question is important for our understanding of Neanderthals because birch bark does not exude visible resin that could be fortuitously discovered and identified as substance from which an adhesive can be made. Birch tar making requires a method that allows to distil tar from the bark and that has been interpreted to require advanced cognitive capacities (e.g., [6]).

Perhaps the best-understood birch tar production technique is the double-pot method. There are written and drawn historical sources (for an overview see: [7]) and there are well-preserved production sites that illustrate the use of this method in the fourteenth century [7, 8]. In a double-pot, bark is heated in a sealed container and tar drips into another connected container. The resulting tar is liquid at room temperature and needs to be reduced by boiling $[8,9]$. This supplementary process of tar reduction is at the origin of the distinction between the terms 'tar'-the first product issued from the process-and

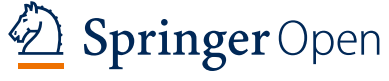

(c) The Author(s) 2021. Open Access This article is licensed under a Creative Commons Attribution 4.0 International License, which permits use, sharing, adaptation, distribution and reproduction in any medium or format, as long as you give appropriate credit to the original author(s) and the source, provide a link to the Creative Commons licence, and indicate if changes were made. The images or other third party material in this article are included in the article's Creative Commons licence, unless indicated otherwise in a credit line to the material. If material is not included in the article's Creative Commons licence and your intended use is not permitted by statutory regulation or exceeds the permitted use, you will need to obtain permission directly from the copyright holder. To view a copy of this licence, visit http://creativecommons.org/licenses/by/4.0/. The Creative Commons Public Domain Dedication waiver (http://creativeco mmons.org/publicdomain/zero/1.0/) applies to the data made available in this article, unless otherwise stated in a credit line to the data. 
'pitch' - the viscous product obtained by reducing the tar. Rageot et al. [10] termed the tar production pathway associated with this method per descensum because tar is separated from the bark by gravity during the process. Another technique, based on a single pot in which birch bark is heated, was proposed for Neolithic tar production $[11,12]$. In this technique, tar is not directly separated from the bark but collected at the bottom of the container. The tar formation conditions in such single pots have recently been investigated and found to require rather precise temperature ranges [13]. These two techniques, the double-pot and the single-pot, may be the best interpretations for prehistoric birch tar production from the Neolithic on. The absence of ceramic containers in the Palaeolithic has given rise to a still ongoing debate about the aceramic counterparts of these techniques that may have been used by Neanderthals. The proposed techniques, all derived from experimentation, can roughly be separated into three groups:

The first group consists of techniques that use earthen structures, most often above ground, in which birch bark is enclosed. The bark is heated by a fire built around the structure (e.g., [14, 15]). Tar is collected in a receptacle that is held in a second chamber, normally below the bark. These methods are similar to the double-pot method in terms of their architecture and it can be expected that tar production follows a per descensum pathway. The second group consists of techniques based on pits in the ground, either open [16] or closed by ash and embers [15] or sediment [17]. The tar forms inside the bark rolls or drips out at the bottom. Those techniques resemble the architecture of Neolithic single-pot methods (for a single-pot technique based on a structure built above ground see: [18]). There is a third group of techniques that are based on fully or partly oxygenated environments: recently, the fully open-air condensation method was introduced [19]. There, tar is condensed on a stone surface from where it is collected by scraping during the process. Condensation tar is relatively solid and ready for use immediately after collection from the surface. A similar technique based on an open-air groove-like structure that is partly covered by a flat stone was proposed by Todtenhaupt et al. [20]. From their description, it is not entirely clear whether tar is condensed on the stone surface in a fully oxygenated environment in this method but, similar to the condensation method, the process takes place above ground. The open-air groove makes use of materials unavailable in the Palaeolithic (plane stone boards) but if future experiments will confirm that it can be performed with natural stones, it might be another interpretation of a potential Neanderthal birch tar making technique.

As it stands, there are three distinct pathways for aceramic birch tar making: per descensum; without separation in a single chamber; and condensation on stone surfaces. Which of these methods was used in the Middle Palaeolithic is still actively debated (e.g., [4, 15, 19, 21-23]). As of now, this discussion has concentrated on the likelihood that one or another technique was used by Neanderthals. One line of argumentation is on the complexity of different techniques: simpler openair techniques have a higher potential to be discovered accidentally $[4,19]$ and may therefore be regarded as a more likely explanation of Palaeolithic tar making. However, another argument was made that the more complex underground techniques are more efficient and are therefore more likely [4]. None of these approaches alone has reached broader consensus so far. Here, we make a third argument in this debate: the performance of different birch tars. In a previous study [19], the authors investigated the lap shear strength of condensation tar, finding a higher strength than tar made per descensum in metal containers. What their study did not do is compare the strength of condensation tar with tar made with other aceramic tar making methods. We therefore conduct a comparative study that aims at understanding the differences in performance (using lap shear strength) of birch tars made with different techniques that may have been used in the Palaeolithic.

The question we attempt to answer with this study is: do different production methods produce birch tar with similar properties in terms of its adhesive performance? To answer this question, we conduct experiments with the aim of comparing birch tar made with the condensation method and the raised structure as described by Kozowyk et al. [15]. There are several ways of understanding the performance of adhesives in different conditions (see for example: [24]). In this paper, we use a type of standard mechanical testing (lap-shear testing) for which published comparative data on other experimental adhesives relevant for Palaeolithic archaeology (e.g., $[25,26])$ are available. If different techniques allow to produce birch tar with similar strengths, then tar performance may be disregarded for the discussion on the likelihood that one technique or another were used in the Palaeolithic. If, on the other hand, we find significant differences between the strengths of birch tar made with different techniques, it becomes worthwhile to discuss the relationship between the investment imposed by specific techniques and the value of the tar that they allow to produce.

\section{Materials and methods}

\section{Sample production}

We made one sample of birch tar with the condensation method [19] and three other samples with raised structures [15]. The condensation method consists of burning 
birch bark near slightly overhanging stone surfaces (Fig. 1a). Tar condenses onto the stone surface adjacent to the flame. The process takes place in a fully aerated environment. Tar was scraped from the stones regularly during the process, using a stone tool (Fig. 1b). We used approximately $170 \mathrm{~g}$ of bark in this experiment.

In our raised structures, rolled birch bark is placed on a grate made of sticks (Fig. 1c) and enclosed in a dome built from wet sediment (Fig. 1d). A fire was built around this dome structure. Tar is collected in a second chamber dug below the grate. We conducted two raised structure experiments simultaneously, each containing receptacles made from aluminium below the grate to minimize loss of the tar. The fire around both structures was kept burning for $4 \mathrm{~h}$ by regularly adding firewood. We opened one structure after four hours of burning time and collected the tar immediately. The other structure was left to cool down over night and the tar was collected the next morning. With this procedure, we hoped to produce two distinct tar samples that were distilled during a similar duration but that had undergone different cooling histories. We expected the quenched sample to have low viscosity and the sample cooled overnight higher viscosity because the remaining heat of the structure had more time to thicken the tar before it was collected. We used approximately $20 \mathrm{~g}$ of bark in each raised structure. A third raised structure was built with a natural stone receptacle in the lower chamber. All other conditions remained the same and the fire was kept burning for the same time. The reason for this third raised structure was not to support the main argument of this study but rather to verify whether the use of aluminium in the other two raised structures has an influence on the resulting tar or whether it can be compared with raised structure tar made with naturally available materials only. Dead bark collected from trees lying on the ground in a forest was used for all experiments.
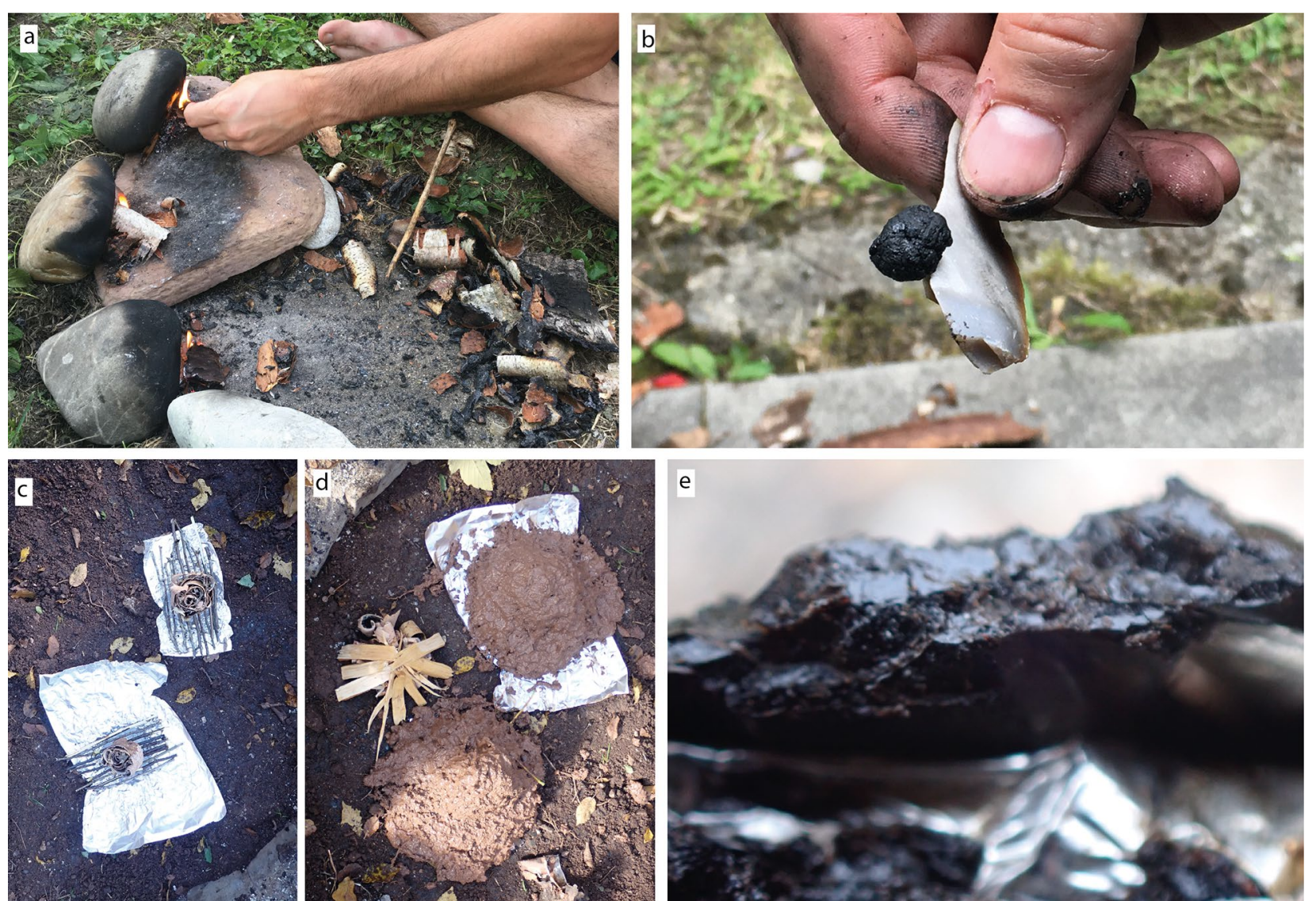

Fig. 1 Experimental set up for the aceramic birch tar making experiments. a Condensation method using several stones simultaneously and the resulting $\operatorname{tar}(\mathbf{b})$; $\mathbf{c}$ two raised structures during construction. Birch bark rolls are placed on grates bade from fine sticks. The lower chamber is covered by aluminium foil to minimize loss of the tar; $\mathbf{d}$ finished raised structure with the sediment covering the bark rolls; $\mathbf{e}$ tar produced in one of the raised structures, still adhering to the aluminium foil receptacle 


\section{Mechanical testing}

The performance of the samples as adhesives was compared using lap-shear testing (see for example: [27]). Lapshear tests, similar to the ones used here, have previously been applied to the study of birch tar and other natural adhesives $[19,25,26]$. All those tests were based on ASTM-D 1002 [28]. The norm was originally intended for adhesively bonded metal specimens (laps) that are tested with a single-lap-joint shear strength test. Such tests are commonly used to evaluate the strength of industrial adhesively bonded joints (e.g., [29]).

The rationale behind this is as follows: ideal brittle materials exhibit linear stress-strain behaviour. In this case, the basic relation under pure shear is $\tau=G \cdot \gamma$, where $\tau$ is the shear stress, $\gamma$ the shear deformation and $G$ the shear modulus. $\gamma$ is then $\tan (\alpha), \alpha$ being the angle of deformation of the flat adhesive cuboid as seen onto its side between the laps. However, materials such as natural tars, that are not ideally brittle, develop a non-linear stress-strain behaviour because of plastic deformation (see the detailed discussion in [30]). A great number of studies have discussed lap-shear tests of non-brittle samples (e.g., [31-34]), stressing the necessity of good control over the deformation for mechanical analyses. This can be achieved with a test similar to ASTM D-5656 [35], requiring a more complicated experimental set-up and that the laps' deformation be measured optically. The requirements for ASTM D-5656 cannot be fulfilled in our laboratories. Therefore, our tests only provide values of the apparent applied shear stress (henceforth $\mathrm{\tau}$ ) at any moment during the test. In this case, $\tau$ is the (tensional) force in $\mathrm{N}$ applied to the bonded area in $\mathrm{mm}^{2}$. Although our tests cannot provide real values of $G$, it is still possible to compare our birch tar samples in terms of this shear stress. Data were therefore plotted in stress/strain diagrams reporting $\tau$ over percent elongation strain.

We performed lap-shear tests with an Instron 4502 universal test machine equipped with kardanic suspended tensile grips. All tests were performed at room temperature $\left(21{ }^{\circ} \mathrm{C}\right.$ in this case). Laps were mounted vertically and pulled apart with a speed of $1 \mathrm{~mm} / \mathrm{min}$. Laps were cut and precision ground from $4 \mathrm{~mm}$ thick Populus sp. plywood measuring $100 \times 25.5 \mathrm{~mm}$. The $25.5 \times 12.5 \mathrm{~mm}$ measuring contact zones $\left(319 \mathrm{~mm}^{2}\right)$ were abraded with 100 grit sand paper. Tests were repeated 10 times for the two raised structure samples produced with aluminium receptacle and the condensation method sample samples (by mistake, 11 times for the condensation method) and 5 times for the raised structure sample produced with a stone receptacle. Tar was applied to the laps by heating it over a flame and then smearing it onto the contact zone before the second lap was bonded to it. Clamping force was not measured but held approximately constant by using manual pressure exerted by the same person in all cases. We let the contact zone cool down to room temperature before testing began. Because this protocol does not allow to visually ascertain that the entire contact zone is covered by tar when gluing together both laps (i.e., there might still be holes in the middle of the bond that cannot be seen when the laps are joined together), we determined the actual bonded areas (in $\mathrm{mm}^{2}$ ) by photographically measuring the extent of the tar-covered zone on both laps after each experiment and averaging both values.

\section{Results}

\section{Birch tar making experiments}

The condensation method produced $0.6 \mathrm{~g}$ in 1-hour working time (the experimental setup, using several stones simultaneously, is shown in Fig. 1a). The recovered tar was solid at room temperature and could not be deformed by hand (Fig. 1b). Building the two raised structures using aluminium receptacle took approximately 30 min altogether. Producing a sufficiently large fire on top of the structures took another $30 \mathrm{~min}$. Building the raised structure with the stone receptacle took $40 \mathrm{~min}$. The fires were kept burning for $4 \mathrm{~h}$. Thus, the stone receptacle sample and the first aluminium receptacle sample required a total time investment of approximately $5 \mathrm{~h}$ each. The second aluminium receptacle structure was left when still surrounded by warm embers and the tar sample was retrieved the next morning. This accounted to a total time investment of $20 \mathrm{~h}$ before $\operatorname{tar}$ was collected (for a discussion of tended and untended technical systems, see: [36]). The $5 \mathrm{~h}$ experiment using the aluminium receptacle produced $1.4 \mathrm{~g}$ of tar with low viscosity that could be deformed by hand. The $20 \mathrm{~h}$ experiment produced $1.65 \mathrm{~g}$ of tar that was solid at room temperature and could not be deformed by hand. Tar yield could not be determined for the raised structure using the stone receptacle because some of the tar was lost and other parts were found to be mixed with sediment (see the photo of the stone receptacle after the experiment in the Additional file 1). We subsampled this sample to only include tar that was not contaminated with sediment.

\section{Lap-shear tests}

Figure 2 shows three typical stress/strain curves from each of the samples. Strength related values are summarised in Table 1. Tar made with the condensation method had a maximal shear stress $\tau_{u}$ of $1.14+0.46-0.52 \mathrm{MPa}$, as averaged from 11 measurements (in this case, maximal shear stress is vaguely equivalent to ultimate tensile strength in tensile testing, hence we use the notation $\tau_{u}$ ). At $\tau_{u}$ catastrophic failure of the bond occurs. Tar made during $20 \mathrm{~h}$ with the raised structure showed similar 


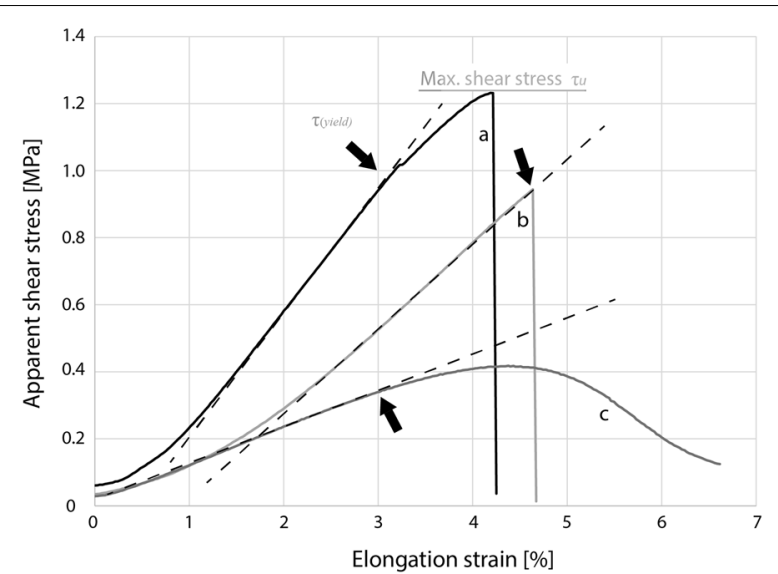

Fig. 2 Stress-Strain curves of birch tar made with the condensation method (a), the raised structure including overnight cool down (b) and the raised structure without cool down phase (c). The samples' shear strength values (i.e., the shear stress values in MPa at which elongation in the samples'stress-strain diagrams cease to be linear) are marked by black arrows. All values obtained from the three samples are marked with the same letters $(\mathbf{a}, \mathbf{b}, \mathbf{c})$ in Table 1

behaviour: it failed catastrophically in a brittle manner (Fig. 2, curve b). $\mathrm{\tau}_{u}$ was $\sim 20 \%$ lower than condensation tar with a mean of $0.95+0.33-0.53 \mathrm{MPa}$.

Tar made in $5 \mathrm{~h}$ with the raised structure had significantly different $\tau_{u}$ at $\sim 65 \%$ below that of condensation tar and $\sim 55 \%$ lower than $20 \mathrm{~h}$-raised structure tar with $0.417+0.45-0.21 \mathrm{MPa}$. Tar made with the raised structure using a stone receptacle had a $\tau_{u}$ of $0.24+0.24-0.15 \mathrm{MPa}$ (some of the stress strain curves of this sample can be seen in the Additional file 1).

Once $\tau_{u}$ is reached, the $5 \mathrm{~h}$-raised structure tar bonds underwent ductile deformation with apparent lowering of the shear stress (Fig. 2, curve c; this is true for aluminium and stone receptacle samples). This observed failure behaviour holds the key to understanding why $\tau_{u}$ might not be the only value to be considered here. Before failure, curves are not linear all along but the relative increase of $\mathrm{\tau}$ slows down at greater elongation strains. Thus, our samples do not behave as brittle solids. Another way to interpret our stress/strain diagrams is therefore by calculating the tangent slope for small deformation intervals on the curves. The stress at which the curve deviates from this tangent (typically after a period of near linearity) is taken to reflect the stress at which creep becomes the dominant deformation (this is vaguely equivalent to the yield strength $\sigma$ in tensile material testing). The method is schematically outlined in Fig. 2 (tangent slopes in broken lines, $\tau_{\text {(yield) }}$ marked by arrows). We call this point the shear strength $\tau_{\text {(yield) }} \cdot \tau_{u}$ can be equal to or greater than $\tau_{\text {(yield), }}$, depending on the moment at which different samples begin to deform plastically. $\tau_{\text {(yield) }}$ values are reported together with their associated strain values in Table 1 . Both values are plotted in Fig. 3 . The scatter plot shows a linear trend, suggesting a roughly linear elastic behaviour of the samples up to their shear strength. Comparing the three tar samples in terms of $\tau_{\text {(yield), }}$, a similar trend emerges as for their $\tau_{u}$ value. Condensation tar has a $\mathrm{\tau}_{\text {(yield) }}$ of $0.86+0.2-0.36 \mathrm{MPa}$; tar made during $20 \mathrm{~h}$ with the raised structure and an aluminium receptacle has a $\mathrm{\tau}_{\text {(yield) }}$ of $0.7+0.4-0.4 \mathrm{MPa}$ (19\% lower); tar made with the raised structure and an aluminium receptacle for $5 \mathrm{~h}$ has a $\mathrm{\tau}_{\text {(yield) }}$ of $0.28+$ $0.32-0.13 \mathrm{MPa}$ (67\% lower than condensation tar). Tar made with the raised structure and a stone receptacle for $5 \mathrm{~h}$ has a $\mathrm{\tau}_{\text {(yield) }}$ of $0.2+0.14-0.13 \mathrm{MPa}$.

\section{Discussion}

\section{Choices made during our experiments and the quality of our data}

Previous authors have performed impact tests along with lap-shear tests [25]. This combined approach may provide a more complete understanding of adhesives as it tests for bonding strength under static conditions like cutting with hafted stone tool and under impact conditions when a projectile is tipped with a hafted stone point. We decided not to test for impact strength as there are no indications that any of the known Palaeolithic birch tar artefacts were used for hafting stone tools to projectiles or handles (compare: [1, 2, 4]).

We chose to use aluminium receptacles for the two main raised structure experiments. In this way, sediment contamination could be limited and a relatively large quantity of uncontaminated tar could be collected after the experiments (because the earthen walls of the lower container were covered by aluminium, Fig. 1). One of the possible effects of this protocol is that the use of aluminium containers, obviously not available in the Palaeolithic, could influence the quality of the tar produced with the raised structures. Although the nature of the container is not expected to have an influence on the volatile components of the raised structure tar (which is lost through evaporation), it appears possible that an aluminium container allows to collect more of the low viscosity fraction of the tar because it is more impermeable than other natural materials. These low viscosity components might be absorbed by a container made from a more porous natural material. We had therefore conducted another raised structure test, using a more porous stone receptacle. The comparison between the tar from this stone container and tar made with the aluminium container, both produced during $5 \mathrm{~h}$, showed that tar collected in a more porous stone container had a $\sim 40 \%$ lower maximum shear stress value and a comparable, although slightly lower, shear 
Table 1 Bonded surfaces, shear strengths and maximum shear stresses from the performed lap-shear tests of each of three analysed samples

\begin{tabular}{|c|c|c|c|c|c|c|}
\hline Tar making method & Surface $1\left(\mathrm{~mm}^{2}\right)$ & Surface $2\left(\mathrm{~mm}^{2}\right)$ & Average $\left(\mathrm{mm}^{2}\right)$ & $\begin{array}{l}\text { Shear strength } \\
\tau_{\text {(yield) }}(\mathrm{MPa})\end{array}$ & Strain (\%) & $\begin{array}{l}\text { Maximum shear } \\
\text { stress } \tau_{u}(\mathrm{MPa})\end{array}$ \\
\hline Condensation & 211.65 & 212.94 & 212.29 & 0.55 & 2.20 & 0.93 \\
\hline Condensation & 304.50 & 305.51 & 305.00 & 1.00 & 4.40 & 1.24 \\
\hline Condensation & 266.04 & 316.95 & 291.49 & 0.82 & 3.90 & 1.32 \\
\hline Condensation (a) & 214.16 & 192.41 & 203.28 & 0.90 & 3.00 & 1.23 \\
\hline Condensation & 278.82 & 283.89 & 281.36 & 1.10 & 4.20 & 1.60 \\
\hline Condensation & 301.49 & 275.78 & 288.63 & 0.80 & 3.80 & 1.14 \\
\hline Condensation & 290.81 & 273.09 & 281.95 & 1.10 & 4.60 & 1.22 \\
\hline Condensation & 275.83 & 294.56 & 285.19 & 1.10 & 4.40 & 1.16 \\
\hline Condensation & 311.12 & 290.88 & 301.00 & 0.80 & 3.30 & 1.31 \\
\hline Condensation & 277.51 & 288.30 & 282.91 & 0.78 & 4.40 & 0.77 \\
\hline Condensation & 322.07 & 287.43 & 304.75 & 0.50 & 2.60 & 0.62 \\
\hline Raised structure $20 \mathrm{~h}$ & 298.66 & 272.99 & 285.83 & 0.90 & 4.30 & 0.99 \\
\hline Raised structure $20 \mathrm{~h}$ & 275.42 & 299.95 & 287.69 & 0.85 & 3.80 & 1.08 \\
\hline Raised structure $20 \mathrm{~h}$ & 304.93 & 337.93 & 321.43 & 0.60 & 3.30 & 1.01 \\
\hline Raised structure $20 \mathrm{~h}$ & 213.96 & 226.67 & 220.32 & 1.10 & 4.20 & 1.15 \\
\hline Raised structure $20 \mathrm{~h}$ & 322.58 & 322.58 & 322.58 & 0.80 & 3.50 & 1.28 \\
\hline Raised structure $20 \mathrm{~h}$ & 303.57 & 264.90 & 284.23 & 0.30 & 3.60 & 0.42 \\
\hline Raised structure 20 h (b) & 260.21 & 264.82 & 262.52 & 0.82 & 4.30 & 0.94 \\
\hline Raised structure $20 \mathrm{~h}$ & 336.37 & 334.96 & 335.66 & 0.55 & 2.80 & 1.10 \\
\hline Raised structure $20 \mathrm{~h}$ & 331.36 & 294.26 & 312.81 & 0.60 & 2.40 & 1.01 \\
\hline Raised structure $20 \mathrm{~h}$ & 342.52 & 350.86 & 346.69 & 0.48 & 2.90 & 0.51 \\
\hline Raised structure $5 \mathrm{~h}$ & 234.67 & 254.45 & 244.56 & 0.45 & 2.70 & 0.21 \\
\hline Raised structure $5 \mathrm{~h}$ & 332.33 & 319.04 & 325.69 & 0.20 & 2.80 & 0.28 \\
\hline Raised structure $5 \mathrm{~h}$ & 322.58 & 322.58 & 322.58 & 0.18 & 5.90 & 0.69 \\
\hline Raised structure $5 \mathrm{~h}$ & 323.80 & 246.75 & 285.27 & 0.15 & 1.80 & 0.22 \\
\hline Raised structure $5 \mathrm{~h}$ & 310.95 & 268.32 & 289.63 & 0.25 & 2.40 & 0.42 \\
\hline Raised structure $5 \mathrm{~h}$ & 322.58 & 322.58 & 322.58 & 0.60 & 3.40 & 0.87 \\
\hline Raised structure 5 h (c) & 324.25 & 295.36 & 309.80 & 0.30 & 2.40 & 0.45 \\
\hline Raised structure $5 \mathrm{~h}$ & 330.95 & 338.62 & 334.79 & 0.30 & 2.60 & 0.37 \\
\hline Raised structure $5 \mathrm{~h}$ & 318.88 & 315.45 & 317.16 & 0.20 & 1.60 & 0.35 \\
\hline Raised structure $5 \mathrm{~h}$ & 286.64 & 299.29 & 292.97 & 0.20 & 2.30 & 0.31 \\
\hline Raised structure $5 \mathrm{~h}$ stone receptacle & 322.58 & 322.58 & 322.58 & 0.07 & 1.60 & 0.09 \\
\hline Raised structure $5 \mathrm{~h}$ stone receptacle & 322.58 & 322.58 & 322.58 & 0.12 & 2.03 & 0.14 \\
\hline Raised structure $5 \mathrm{~h}$ stone receptacle & 322.58 & 322.58 & 322.58 & 0.34 & 1.94 & 0.37 \\
\hline Raised structure $5 \mathrm{~h}$ stone receptacle & 322.58 & 322.58 & 322.58 & 0.12 & 3.47 & 0.13 \\
\hline Raised structure $5 \mathrm{~h}$ stone receptacle & 322.58 & 322.58 & 322.58 & 0.33 & 2.33 & 0.48 \\
\hline
\end{tabular}

Letters in brackets in the first column are the numbers of stress/strain diagrams shown in Fig. 2

strength value. Thus, using an aluminum container has the opposite effect to what we expected. This result suggests that the use of aluminum containers might cause the shear strength of tar made with the raised structure to be overestimated. As it stands, our quantitative comparison between condensation method tar and raised structure tar must be regarded with caution, although the overall trend is most likely correct based on our results from this comparison.
We also found that there are complex stress distributions present in the bonded areas of birch tar analysed with lap-shear tests, leading to non-linear behaviour even before failure. This can be expected to depend (at least in part) on the thickness of the bond and the quality of the bonding surface (see for example: [34]). Measuring bond thickness was not possible with the wooden laps used for this study, as their thickness is not uniform across the bonded surface (i.e., they were not sufficiently 


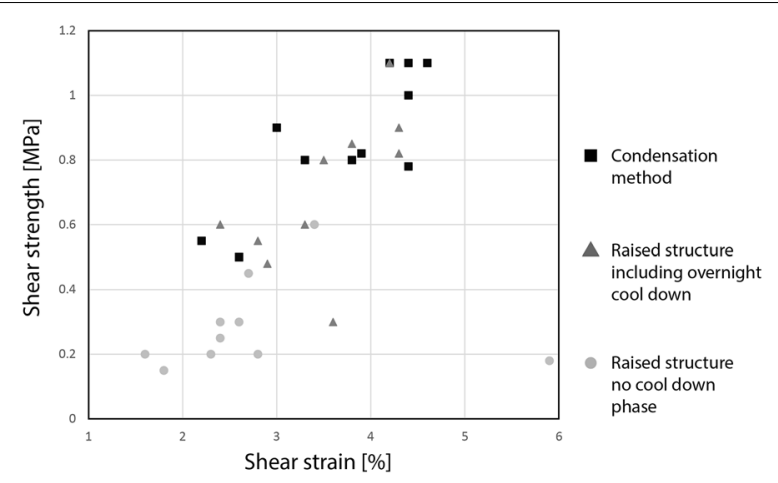

Fig. 3 Shear strength in MPa plotted over shear strain in percent. Note the near-linear trend, suggesting that samples exhibit nearly brittle behaviour below their shear strength

plan parallel). Measurements were therefore repeated at least ten times for the samples (except for tar made with a stone receptacle that was repeated 5 times, as this was only done to verify the validity of our experimental protocol). As highlighted above, we consider only the apparent shear stresses $\tau$, attributing all measured forces to be shear only. This is not entirely true, as can be seen from the curves in Fig. 2, which are not linear even for tars that fail catastrophically. One of the reasons for this is that organic materials, such as some of our birch tar samples, do not respond to stress with elastic deformation up to their failure. They show plastic deformation by viscous processes or other creep phenomena. Furthermore, horizontal elongation in lap-shear tests cannot be expected to be linear because the tar samples' thickness at the bond varies with elongation (depending on Poisson's ratio of the adhesives). Thus, $\tau_{u}$ recorded by lap-shear tests is not a good indicator of the resilience of natural tars against shear. We still use this value here because previous authors have provided lap-shear data $[19,25,26]$ with which our data may be comparable. Although our tests cannot yield absolute values of $G$, our approach to measuring $\tau_{u}$ provides comparability with previous works $[25$, 26] that reported similar values.

\section{The performance of birch tar made with different production techniques}

What does performance of adhesives made in the Stone Age actually mean? Two cases may be distinguished. Adhesives that have to work only one time (as may be true for a projectile hafting) can most likely be qualified by either the maximum shear stress they endure (including a plastic deformation modifying the shape of the joint permanently) or by the total energy they absorb during the shearing process. For such a rupture energy evaluation, other experiments with better strain control are needed. The other case consists of adhesives used for repeated actions (cutting, scraping, etc.). These may be better qualified by shear strength $\tau_{\text {(vield) }}$. A nearly brittle nature of the failure (the sample behaving almost elastically until the breaking point) might in this case be an advantage because tools either hold or break loose. A plastically deformed haft will perform less well in successive use cycles.

Our results highlight that tar made with the condensation method is similarly, although slightly more, performant when used as adhesive than tar made with the raised structure can be. A larger difference exists when raised structure tar is collected from the structure directly after the surrounding fire burned out. Our $\tau_{u}$ measured on $5 \mathrm{~h}$-raised structure birch tar $(0.417+$ $0.45-0.21 \mathrm{MPa})$ is in accordance with, although lying slightly above, previously published lap-shear values of birch tar made with the double-pot method (using a metal container) that was subsequently boiled to thicken it $(0.32+0.19-0.18 \mathrm{MPa}$, see: [26]). The raised structure is a good approximation of the double-pot architecture in aceramic conditions (for a detailed description of the double-pot, see: [7]) and it also appears to produce birch tar with similar properties. It is noteworthy however, that the aceramic raised structure allows the production of birch tar with similar strength as the metal-based double-pot without requiring the supplementary step of tar reduction by boiling. The reason for this might be a better availability of oxygen in the raised structure due to incomplete sealing because of the wet sediment. The strength of the raised structure tar can be improved by a factor of two, if the tar is allowed to cool slowly overnight. The reason for this might be oxidative reactions in the slowly cooling tar or tar reduction by degassing. Only further studies may shed light on these processes. The condensation method produced birch tar with the highest $\tau_{u}$ of the tested production methods. Our maximal strength $(1.14+0.46-0.52 \mathrm{MPa})$ is well in accordance with previously published strength values of condensation $\operatorname{tar}(1.145+0.403-0.438 \mathrm{MPa}$, see: [19]).

\section{The cost and return of birch tar made with different techniques}

The differences in adhesive performance of our samples are best discussed with regards to the investment in time and effort required by different production methods. Recently, Blessing and Schmidt [36] found that the raised structure is the most efficient of the aceramic production techniques in terms of material requirement (supporting previous arguments made by: [15]). However, it can be inferred from the data in Badino et al. [37] that birch bark was readily available in northern Europe during the Late Middle Palaeolithic. It is therefore unclear whether 
efficiency in terms of required bark over tar yield may possibly have imposed constraints for making the birch tar artefacts from Zandmotor and Königsaue. Another raw material-related factor is that the raised structure requires the collection of firewood, imposing supplementary constraints on the environment in which tar is made and which are absent for the condensation method.

If time investment is compared for both techniques, the difference between the raised structure and the condensation method seems to be negligible. Both produced similar amounts of tar per hour in most experiments [36]. It is also noteworthy that the raised structure imposes a minimum requirement of time, which is roughly $4-5 \mathrm{~h}$ [15], while the condensation method allows to produce usable amounts of tar in approximately one hour [36] (e.g., the $0.87 \mathrm{~g}$ weighing smaller birch tar piece from Königsaue can be produced in $\sim 1 \mathrm{~h} 20$; these times cannot be compared in terms of attention required, see for example [36], but they do still represent time requirements). Thus, in terms of time requirement, the condensation method may be far more advantageous if tar is needed rapidly. In the light of our finding that condensation tar is similar to tar made with the raised structure in $20 \mathrm{~h}$ and superior to raised structure tar made in $5 \mathrm{~h}$ (in terms of shear strength at least), we note that this simple open-air technique provides the best value for the time investment it requires. Whether raised structure tar produced without the cooling phase may be improved by a supplementary step of tar reduction, in which the low viscosity tar is boiled over an open flame to produce a more viscous product, cannot be answered at this point. However, additional cooking of the tar would require larger investment than investigated here.

\section{Conclusion}

The relationship between the quality of the tar and the investment required for its production highlights the condensation method as the most likely of all known aceramic birch tar production techniques. There are however other adhesives that were used by Neanderthals (such as bitumen, see: [38], and pine resin, see: [39]). Data on the adhesive strength of pine resin suggest similar strength to birch tar made with the condensation method and even slightly higher adhesive strength either when an additive is added or if it is reduced by boiling [26]. The strength can be further improved by adding complex mixtures of additives [25]. Whether these differences are significant for our understanding of adhesives in the Middle Palaeolithic cannot be decided based on our study but we note that among all currently discussed birch tar production techniques, the simplest and most expedient condensation method provides the strongest tar.

\section{Supplementary Information}

The online version contains supplementary material available at https://doi. org/10.1186/s40494-021-00621-1.

Additional file 1: Figure S1. Side (left) and top view (right) of the stone receptacle used in the raised structure (production time $5 \mathrm{~h}$ ). Note that there is still tar adhering to the stone. This tar is contaminated with sediment. The middle portion was scraped to obtain tar without sediment impurities. Figure S2. Three stress strain curves obtained from lap shear tests on the raised structure birch tar sample using a stone receptacle and a total production time of $5 \mathrm{~h}$.

\section{Acknowledgements}

F. Lauxmann contributed to the experiments and R. lovita assisted with the condensation method experiments.

\section{Authors' contributions}

PS and MB conceived the study. PS, MAB, TJK and KGN analysed the data and wrote the paper. All authors read and approved the final manuscript.

\section{Funding}

Open Access funding enabled and organized by Projekt DEAL. PS received funding from the Deutsche Forschungsgemeinschaft (DFG) (Grant Number SCHM 3275/3-1) and MAB received a fellowship from the Landesgraduiertenförderung Baden-Württemberg for the project Evolution of Cultura Modernity. We also acknowledge support by Open Access Publishing Fund of University of Tübingen

\section{Availability of data and materials}

All data generated or analysed during this study are included in this published article.

\section{Declarations}

Competing interests

The authors declare that they have no competing interests.

\section{Author details}

${ }^{1}$ Department of Early Prehistory and Quaternary Ecology, Eberhard Karls University of Tübingen, Tübingen, Germany. ${ }^{2}$ Applied Mineralogy, Department of Geosciences, Eberhard Karls University of Tübingen, Tübingen, Germany.

Received: 23 June 2021 Accepted: 23 October 2021

Published online: 01 November 2021

\section{References}

1. Mazza PPA, Martini F, Sala B, Magi M, Colombini MP, Giachi G, et al. A new Palaeolithic discovery: tar-hafted stone tools in a European Mid-Pleistocene bone-bearing bed. J Archaeol Sci. 2006;33(9):1310-8. https://doi. org/10.1016/j.jas.2006.01.006.

2. Grünberg J, Gratsch H, Baumer U, Koller J. Utersuchung der mittelpaläolithischen "Harzreste" von Königsaue, Ldkr. Aschersleben-Stassfurt. Jahresschr Mitteldeutsch Vorgeschich. 1999;81:7-38.

3. Koller J, Baumer U, Mania D. High-tech in the middle Palaeolithic: Neandertal-manufactured pitch identified. Eur J Archaeol. 2001;4(3):385-97. https://doi.org/10.1179/eja.2001.4.3.385

4. Niekus MJLT, Kozowyk PRB, Langejans GHJ, Ngan-Tillard D, van Keulen $\mathrm{H}$, van der Plicht J, et al. Middle Paleolithic complex technology and a Neandertal tar-backed tool from the Dutch North Sea. Proc Natl Acad Sci. 2019. https://doi.org/10.1073/pnas.1907828116.

5. Pawlik A, Thissen J. Hafted armatures and multi-component tool design at the Micoquian site of Inden-Altdorf, Germany. J Archaeol Sci. 2011;38:1699-708.

6. Roebroeks W, Soressi M. Neandertals revised. Proc Natl Acad Sci. 2016;113(23):6372. https://doi.org/10.1073/pnas.1521269113. 
7. Kurzweil A, Todtenhaupt D. Technologie der Holzteergewinnung. Acta Praehist Archaeol. 1992;23:63-91.

8. Krabath S, Schöneburg P. Pechgewinnung in der sächsischen Oberlausitz. Mitt Dtsch Ges Archäol Mittelalt Neuzeit. 2016;29:243-50.

9. Meijer R, Pomstra D. The production of birch pitch with hunter-gatherer technology: a possibility. Exp Archäol Eur. 2011;10:199-204.

10. Rageot M, Théry-Parisot I, Beyries S, Lepère C, Carré A, Mazuy A, et al. Birch bark tar production: experimental and biomolecular approaches to the study of a common and widely used prehistoric adhesive. J Archaeol Method Theory. 2019;26(1):276-312. https://doi.org/10.1007/ s10816-018-9372-4.

11. Czarnowski E, Neubauer D, Schwörer P. Zur herstellung von birkenpech im Neolithikum. Acta Praehist Archaeol. 1990;22:169-73.

12. Neubauer-Saurer D. Birkenpechproduktion im Neolithikum (ein mögliches verfahren). In: Piotrowski WB, Piotrowski W, editors. Poceeding of the first international symposium on wood tar and pitch. Warsaw: State Archaeological Museum; 1997.

13. Koch TJ, Schmidt P. The formation conditions of birch tar in oxygendepleted environments. Archaeol Anthropol Sci. 2021;13(6):92. https:// doi.org/10.1007/s12520-021-01352-x.

14. SchenckT, Groom P. The aceramic production of Betula pubescens (downy birch) bark tar using simple raised structures. A viable Neanderthal technique? Archaeol Anthropol Sci. 2018;10(1):19-29. https://doi.org/10.1007/ s12520-016-0327-y.

15. Kozowyk PRB, Soressi M, Pomstra D, Langejans GHJ. Experimental methods for the Palaeolithic dry distillation of birch bark: implications for the origin and development of Neandertal adhesive technology. Sci Rep. 2017;7(1):8033. https://doi.org/10.1038/s41598-017-08106-7.

16. Pawlik A. Die mikroskopische analyse von steingeräten. Experimenteauswertungsmethoden—artefaktanalyse. Tübingen: Archaeologica Venatoria; 1995. p. 340.

17. Groom P, SchenckT, Pedersen GM. Experimental explorations into the aceramic dry distillation of Betula pubescens (downy birch) bark tar. Archaeol Anthropol Sci. 2015;7(1):47-58. https://doi.org/10.1007/ s12520-013-0144-5.

18. Osipowicz G. A method of wood tar production, without the use of ceramics. Reconstr Exp Archaeol EuroREA. 2005;2:11-7.

19. Schmidt P, Blessing M, Rageot M, lovita R, Pfleging J, Nickel KG, et al. Birch tar production does not prove Neanderthal behavioral complexity. Proc Natl Acad Sci. 2019;116(36):17707. https://doi.org/10.1073/pnas.19111 37116.

20. Todtenhaupt D, Elsweiler F, Baumer U. Das pech des Neandertalers—eine möglichkeit der herstellung. Experimentelle archäologie in Europa. Oldenburg: Isensee Verlag; 2007. p. 155-61.

21. Villa P, Roebroeks W. Neandertal demise: an archaeological analysis of the modern human superiority complex. PLoS ONE. 2014;9(4): e96424. https://doi.org/10.1371/journal.pone.0096424.

22. Schmidt $P$, Rageot $M$, Blessing $M$, Tennie $C$. The Zandmotor data do not resolve the question whether Middle Paleolithic birch tar making was complex or not. Proc Natl Acad Sci. 2020;117(9):4456. https://doi.org/10 1073/pnas.1919564117.

23. Kozowyk PRB, Langejans GHJ, Dusseldorp GL, Niekus MJLT. Reply to Schmidt et al.: interpretation of Paleolithic adhesive production: combining experimental and paleoenvironmental information. Proc Natl Acad Sci. 2020;117(9):4458. https://doi.org/10.1073/pnas.1920933117.

24. Kozowyk PRB, Poulis JA. A new experimental methodology for assessing adhesive properties shows that Neandertals used the most suitable material available. J Hum Evol. 2019;137: 102664. https://doi.org/10. 1016/j.jhevol.2019.102664.

25. Kozowyk PRB, Langejans GHJ, Poulis JA. Lap shear and impact testing of ochre and beeswax in experimental middle stone age compound adhesives. PLoS ONE. 2016;11(3): e0150436. https://doi.org/10.1371/journ al.pone.0150436.

26. Kozowyk PRB, Poulis JA, Langejans GHJ. Laboratory strength testing of pine wood and birch bark adhesives: a first study of the material properties of pitch. J Archaeol Sci Rep. 2017;13:49-59. https://doi.org/10.1016/j. jasrep.2017.03.006.

27. Lancaster JF. Metallurgy of welding. Sawston: Woodhead Publishing; 1999. p. 464.

28. ASTM-D1002-01. Standard test method for apparent shear strength of single-lap-joint adhesively bonded metal specimens by tension loading (metal-to-metal). West Conshohocken: ASTM International; 2019. https:// doi.org/10.1520/D1002-01.

29. Kagalkar N, Srinivas S, Dhananjaya BR. Determination of shear strength and failure type of the sealant using lap shear test. Mater Today Proc. 2018;5(1, Part 3):2752-8. https://doi.org/10.1016/j.matpr.2018.01.061.

30. Tong L. Bond strength for adhesive-bonded single-lap joints. Acta Mech. 1996;117(1):101-13. https://doi.org/10.1007/BF01181040.

31. Tomblin JS, Yang C, Harter P. Investigation of thick bondline adhesive joints. Washington: U.S. Department of Transportation, Administration USDoTFA; 2001

32. Stringer LG. Comparison of the shear stress-strain behaviour of some structural adhesives. J Adhes. 2007;18(3):185-96. https://doi.org/10.1080/ 00218468508079682.

33. Raos P, Kozak D, Lucić M. Stress-strain analysis of single-lap tensile loaded adhesive joints. AIP Conf Proc. 2000;908(1):1093-9.

34. da Silva LFM, Rodrigues TNSS, Figueiredo MAV, de Moura MFSF, Chousal JAG. Effect of adhesive type and thickness on the lap shear strength. J Adhes. 2006;82(11):1091-115. https://doi.org/10.1080/002184606009485 11.

35. ASTM-D5656. Standard test method for thick-adherend metal lap-shear joints for determination of the stress-strain behavior of adhesives in shear by tension loading. West Conshohocken: ASTM International; 2004. https://doi.org/10.1520/D5656-04.

36. Blessing M, Schmidt P. On the efficiency of Palaeolithic birch tar making. JArchaeol Sci Rep. 2021;38:103096.

37. Badino F, Pini R, Ravazzi C, Margaritora D, Arrighi S, Bortolini E, et al. An overview of Alpine and Mediterranean palaeogeography, terrestrial ecosystems and climate history during MIS 3 with focus on the Middle to Upper Palaeolithic transition. Quatern Int. 2020;551:7-28. https://doi.org/ 10.1016/j.quaint.2019.09.024.

38. Boëda E, Bonilauri S, Connan J, Jarvie D, Mercier N, Tobey M, et al. Middle Palaeolithic bitumen use at Umm el Tlel around 70,000 BP. Antiquity. 2008;82(318):853-61. https://doi.org/10.1017/S0003598X00097623.

39. Degano I, Soriano S, Villa P, Pollarolo L, Lucejko JJ, Jacobs Z, et al. Hafting of Middle Paleolithic tools in Latium (central Italy): new data from Fossellone and Sant'Agostino caves. PLoS ONE. 2019;14(6):e0213473.

\section{Publisher's Note}

Springer Nature remains neutral with regard to jurisdictional claims in published maps and institutional affiliations. 